\title{
A preliminary screening report of HCV positive cases in district Kotli conducted in 2006 and further epidemiology of the virus in Pakistan
}

\begin{abstract}
Hepatitis $\mathrm{C}$ virus (HCV) infection is the most distressing health problem worldwide, a global health care dilemma. The spectrum of hepatitis $\mathrm{C}$ virus (HCV) in developing countries is quite different from that of developed ones. In developing countries $\mathrm{HCV}$ is prevalent in urban and rural communities, men and women, educated and less-educated individuals, and among most age groups. Less government supported data collection programmes, screening, prevention and treatment provisions further aggravate the situation. The first description of HCV in Pakistan was in 1992. Today Pakistan has the second largest number of Hepatitis $\mathrm{C}$ virus infections in the world. Efforts to quantitatively and characterize the level and trend of the HCV epidemic in Pakistan progressively initiated in 1980. The present paper where discusses the evolution and current epidemiology of HCV in Pakistan, it also reports one of an initial screening tests of anti HCV positive cases at Chinar lab, Kotli Pakistan. Out of 2060 samples collected from jaundiced patients, 249 were found positive for HCV (12\%). Out of the positive cases $44 \%$ were male and $56 \%$ wee female. Less than 18 years male percentage was $93 \%$ and that of females was $7 \%$. Whereas, the percentage of above 18 years male and female was exactly opposite i.e. $93 \%$ females \& $7 \%$ males. The major assessed risk factors then were, cessarian section, and other surgical procedures, non-screened blood transfusions, and other procedures as parental infusions, piercing, and tattooing. We conclude that efforts for HCV screening, prevention and control in Pakistan were started at government and private levels long before. However despite these efforts the current data suggest that the disease still presents a major health threat in Pakistan.
\end{abstract}

Keywords: HCV, screening, epidemiology, parental infusions, health threat, blood-borne viruses, syringes, geographical areas, epidemiologic data, sera
Volume 2 Issue 2 - 2018

\author{
Masood Ahmad,' Nosheen Karim, ${ }^{2}$ Raja \\ Mehtab Khan, ${ }^{3}$ Nusrat Zareen ${ }^{4}$ \\ 'Infection control Specialist, Ministry of Health, Saudi Arabia \\ ${ }^{2}$ Lecturer immunology, Northern Border University, Saudi \\ Arabia \\ ${ }^{3}$ Medical Technologist, Chinar laboratory, Kotli , Pakistan \\ ${ }^{4}$ Anatomy department, University of Taif, Saudi Arabia
}

\begin{abstract}
Correspondence: Nusrat Zareen, Anatomy department, College of Medicine, University of Taif, KSA, Tel 0096658290 I82,
\end{abstract} Email Nusrat.zareen@gmail.com

Received: March 10, 2018 | Published: April 05, 2018

\section{Background}

Hepatitis $\mathrm{C}$ virus is one of the most widespread blood-borne viruses and is related with momentous morbidity and mortality. It is a major global health care dilemma. It is the 7th leading cause of mortality globally $1 .{ }^{1}$ Therapeutic injections by contaminated, re-used syringes, transfusion of unsafe blood and re-use of razors are major factors for the spread of hepatitis $\mathrm{C}$ in the general population. The WHO estimates that more than $3 \%$ of the world population (WHO 2014) is living with hepatitis C. Globally, hepatitis C disease burden has a variable geographical distribution whereas, high prevalence is observed in East and Central Asia followed by North Africa and Middle Eastern counties. As larger population resides in the Asian and African regions, the highest prevalence is observed there as compare to rest of the world. ${ }^{2}$ Almost $3.7 \%$ of Eastern Asia, 3.6\% of Middle East and $3.4 \%$ of South Asia populations are struggling with hepatitis C. ${ }^{3}$ The prevalence of $\mathrm{HCV}$ infection was estimated to be $6 \%$ in Pakistan, in year 2011. ${ }^{4}$ Today HCV infection is endemic in Pakistan. ${ }^{5}$ According to a recent report, the incidence of the disease has increased from $4.7 \%$ to $6.8 \%$ within a couple of years. ${ }^{6}$ Unfortunately, low literacy level, inadequate public health facilities and lack of awareness are main reasons behind insufficiency of significant data about the high incidence of the disease in Pakistan. Several studies have reported various $\mathrm{HCV}$ infection rates in different geographical areas and ethnic groups in Pakistan. ${ }^{7}$ Available data indicate that infection with HCV varies considerably by country and region. However, the true burden of disease is not well known in many countries, because capacity is limited for collecting epidemiologic data. In contrast, the mode of transmission is fairly well defined and most often involves exposure to contaminated needles or syringes, although the means by which this exposure occurs differs by country. ${ }^{8}$

\section{Introduction}

Understanding of HCV epidemiology in Pakistan has been greatly improved by the numerous studies conducted over the span of the past two decades. Recent years have seen an increased focus among Pakistani researchers on the study of HCV prevalence patterns and frequency distribution of its genotypes. Results from recent studies were pooled to produce a comprehensive map of $\mathrm{HCV}$ prevalence in Pakistan at the district level (Figure 1). ${ }^{9}$ Hepatitis $\mathrm{C}$ is a major health problem in Pakistan, and according to an estimate about 10 million people are infected with this virus. ${ }^{10}$ Exact prevalence is not known but is estimated to be around 3.8\% according to unofficial, unpublished reports. ${ }^{11}$ Hepatitis $\mathrm{C}$ is endemic in Pakistan with a $40 \%$ raise in the incidence of the disease conferring to resent reports. Data of the last five years from different districts of the country show an abrupt elevation in HCV seroprevalence. HCV genotype 3a remains to be the most prevalent in Pakistan $(61.3 \%){ }^{12}$

\section{Epidemiology of HCV in Pakistan}

The recent epidemiology of HCV in Pakistan has been studied in detail. In federal capital Islamabad, the prevalence reported in recent years is $33 \%$ in selected group of population. Whereas, studies 
conducted in different districts of the Khyber Pakhtun Khwa (KPK) province revealed anti-HCV seroprevalence in district Mardan and Mansehra, from Azad Kashmir districts Kotli and Mirpur. Studies of HCV prevalence over the last five years in Sindh Province included the districts of Karachi and Hyderabad. A resent research conducted on $\mathrm{HCV}$ frequency in the district of Baluchistan included the provinces of Quetta and Sibi. This review reveals that there are only limited

Table I Prevalence of HCV genotypes in selected cities from five major geographical divisions of Pakistan ${ }^{13}$

\begin{tabular}{lllllll}
\hline $\begin{array}{l}\text { Major geographical } \\
\text { distribution of Pakistan }\end{array}$ & Selected cities & \multicolumn{5}{l}{ Frequency of HCV genotypes (\%) } \\
\hline & & Ia & I b & 2a & 3a & 3b \\
\hline \multirow{3}{*}{ Punjab } & Gora & I0.9 & 2.8 & 0.4 & 61.1 & 24.8 \\
& Shakargarh & II.9 & 2.7 & 0.3 & 59.2 & 25.9 \\
Sindh & Kashmore & 9.2 & 2.9 & 0.9 & 64.2 & 22.8 \\
& Kandiaro & 20.9 & 2.6 & 0.7 & 59.8 & 16 \\
Balochistan & Loratat & 21.6 & 2.3 & 0.4 & 57.2 & 18.4 \\
& Ouetta & 20.2 & 2.9 & 0.9 & 56.9 & 19.1 \\
Khalbar Pakhtoon Khaw & Haripur & 12.2 & 2.8 & 0.7 & 59.4 & 24.8 \\
& Hangue & II.9 & 2.7 & 0.9 & 56.9 & 27.6 \\
\multirow{3}{*}{ Azad Kashmir } & Kotli & 10.1 & 1.4 & 0.4 & 66.2 & 27.9 \\
& Baqh & 9.8 & 1.9 & 0.3 & 68.3 & 19.7 \\
\hline
\end{tabular}

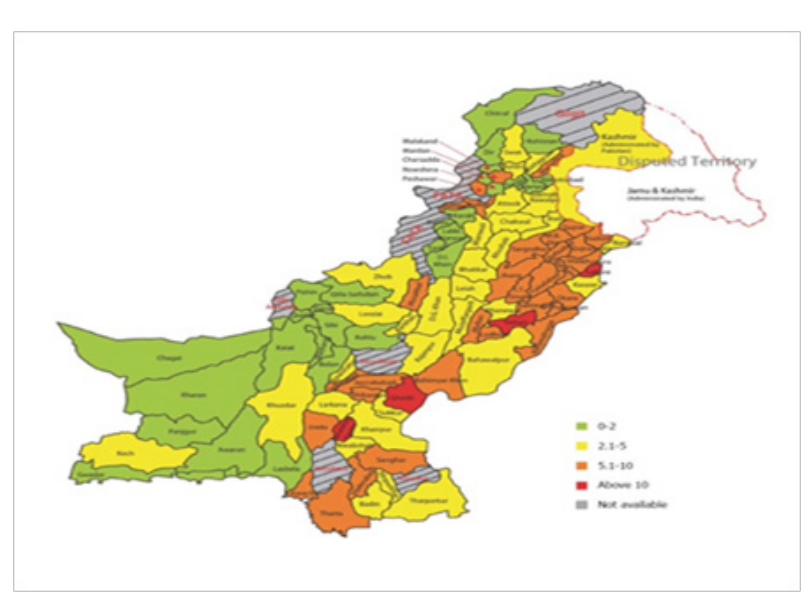

Figure I Hepatitis C virus seroprevalence in Pakistan at the district level. ${ }^{9}$

\section{Objective}

The objective of this project was to screen out the HCV antibody positive cases in jaundiced patients presenting to a local private gastroenterologist and further referred to $\mathrm{HCV}$ management centres.

\section{Material and methods}

HCV screening test was performed in jaundiced patients, presenting to private gastroenterologist and further referred to Chinar lab, Distric Kotli Pakistan. A total of 2060 cases were referred in the year 2006, which included 991 males and 1069 females. About 3-5 $\mathrm{ml}$ of blood was collected from the patients and serum was separated number of studies available in some high prevalence districts, such as Sibi, Mirpur and Kotli. Unfortunately, lack of reports from tribal areas, Gilgit Baltistan, indicates the need for comprehensive studies in these areas (Table 1). ${ }^{13}$ Having reported the present epidemiology of the disease in different districts of Pakistan, we report a preliminary data collected in district kotli, azad jummu Kashmir Pakistan that was collected in year 2006.

by centrifugation. Sera were tested for anti HCV antibodies by third generation ELISA (ERBA diagnostics Mannheim GmbH, Germany) as per the manufacturers' instructions. Personal biodata was collected along with possible determining possible exposure factor by taking retrospective history.

\section{Results}

Out of 2060 samples 249 were found positive for HCV (12\%). Out of the positive cases $44 \%$ were male and $56 \%$ wee female. Less than 18 years male percentage was $93 \%$ and that of females was $7 \%$. Whereas the percentage of above 18 years male and female positive cases was exactly opposite i.e $93 \%$ females \& $7 \%$ males. The anticipated risk factor or cause of infection was also assessed retrospective history (Table 2).

Table 2 Assessed risk factors for anti HVC antibodies positive cases

\begin{tabular}{llll}
\hline Sr $\neq \quad$ Risk factor exposure & $\begin{array}{l}\text { No of } \\
\text { cases }\end{array}$ & $\begin{array}{l}\text { Percentage of ant HCV } \\
\text { antibodies positive } \\
\text { cases }\end{array}$ \\
\hline I & $\begin{array}{l}\text { Delivery by Cessarian } \\
\text { section }\end{array}$ & 87 & 36 \\
2 & $\begin{array}{l}\text { Surgical operation } \\
3\end{array}$ & 20 & 8 \\
$4 \quad$ & $\begin{array}{l}\text { Jaundice } \\
\text { Blood transfusion }\end{array}$ & 10 & 4 \\
5 & $\begin{array}{l}\text { Others (injection, } \\
\text { piercing, tattooing) }\end{array}$ & 101 & 40 \\
\hline
\end{tabular}




\section{Discussion}

This is one the initial reported screening data for HCV positive cases in a remote area of Pakistan i.e. Kotli. Back in 2006, the information on HCV epidemiology was almost non-existent. First discovered in $1989,{ }^{13} \mathrm{HCV}$ infection became a global epdemic ever since then. Underdeveloped countries, with low literacy rate, and high poverty rate, had more hurdles in proper screening test for this infection. Remote areas of Pakistan like Kotli, where private and also mal practice of doctors and para medical personal topped by lack of public awareness contributed vastly to the spread of the infection. Hepatitis C Virus (HCV) infection has become a global public health concern and demanding high priority efforts for primary prevention, treatment, and awareness campaigns among the public. The determinants of HCV are common in developed and developing countries; the major source of $\mathrm{HCV}$ infection is unprotected sexual contact, infected blood transfusion, sharing of infected needles among the drug users, and perinatal transmission. ${ }^{14}$ The first description of HCV in Pakistan was in 1992. In this study, 45 histologically confirmed cases of chronic liver disease were tested for the presence of anti-HCV antibodies. Anti-HCV antibodies were detected in six patients. Of the six, two had chronic hepatitis, three had cirrhosis and one developed HCC. ${ }^{15}$ Today Pakistan has the second largest number of Hepatitis $\mathrm{C}$ virus infections in the world. ${ }^{16}$

Most recently an age-structured mathematical model has been developed and analysed to describe transmission dynamics over the years 1980-2050. The model is fitted to a nationally-representative survey and a comprehensive database of systematically-gathered $\mathrm{HCV}$ antibody $(\mathrm{Ab})$ prevalence data. Prevalence and incidence varied by age, and the majority of new infections are found to be occurring in the 20-39 age groups. Prevalence and incidence of HCV in Pakistan has been slowly declining for two decades - According to this report Pakistan is enduring a large epidemic that will persist for decades if not controlled. Nearly $10 \%$ of global infections are in Pakistan, with about 200,000 additional infections every year. According to this report rapid and mass scale-up of prevention and treatment programs are critically needed..$^{16} \mathrm{HCV}$ antibody $(\mathrm{Ab})$ prevalence in Pakistan is estimated Pakistan is estimated to be $4.9 \%$ in 2007-2008. ${ }^{17}$ However Pakistan's epidemic remains overall poorly understood and characterized till date. ${ }^{4}$ Past and potential future trends of the $\mathrm{HCV}$ epidemic in Pakistan need to be established. Unlike other countries with large epidemics where multiple nationally-representative and population-based prevalence surveys have been conducted, ${ }^{18}$ only one such survey was conducted in Pakistan and nearly a decade ago. ${ }^{19}$ While HCV epidemics appear to be contracting across countries globally, it has been suggested that Pakistan's epidemic may be bucking this trend with a growing epidemic. ${ }^{20}$

Different lines of evidence further suggest a high ongoing $\mathrm{HCV}$ incidence, driven possibly by various healthcare-related procedures, such as reuse of injections, inadequate blood screening, and deficient infection control, among others. ${ }^{12}$ Efforts to quantitatively and characterize the level and trend of the HCV epidemic in Pakistan progressively initiated in 1980. Different small projects and data compilation at district basic health units and district levels led to awareness and highlighted the upcoming danger of the epidemic. The reported project here is an example of a small but vital data compiled at a remote and neglected district of Pakistan in 2006. Ultimately Pakistan has evolved in its screening and epidemiology compilation, aiming to forecast its potential evolution up to 2050
Specifically, we assessed the temporal evolution and age distribution of $\mathrm{HCV} \mathrm{Ab}$ prevalence, chronic infection prevalence, number of infected individuals, annual number of new HCV infections, and incidence rate, thereby providing a comprehensive characterization of this epidemic, past, present, and future. ${ }^{16}$ Despite the forecasted decline in HCV chronic infection prevalence over the coming decades in Pakistan, prevalence will remain at high levels, far higher than the global target of HCV elimination by $2030 .{ }^{21}$ In addition there are studies that show that both HCV prevalence and incidence have been declining for about two decades in Pakistan, but very slowly. ${ }^{16}$ The observed declines in $\mathrm{HCV} \mathrm{Ab}$ prevalence, chronic infection prevalence, incidence, and incidence rate) could be attributed to several factors, none of which is certain or conclusive. Increasing coverage of blood screening, and possibly improved infection control in at least a segment of the healthcare system. ${ }^{25} \mathrm{~A}$ related factor could be increasing awareness about the virus and its transmission patterns within the healthcare system or in the general public. ${ }^{26}$ Despite this slow decline in it is estimated that there are currently over 8 million $\mathrm{HCV} \mathrm{Ab}$ positive individuals, and over 6 million chronically-infected individuals that are in need of treatment - nearly $10 \%$ of the global number of chronic infections in Pakistan. ${ }^{27}$

\section{Conclusion}

In conclusion, Pakistan is enduring an $\mathrm{HCV}$ epidemic of historical proportions. Although the epidemic appears to be contracting, the rate of decline is slow and chronic infection prevalence will persist at levels much higher than the global target of elimination by 2030. Over six million people are in need of treatment in Pakistan today.

\section{Acknowledgement}

None.

\section{Conflict of interest}

The authors declare there is no any conflict of interest.

\section{References}

1. Stanaway JD, Flaxman AD, Naghavi M, et al. The global burden of viral hepatitis from 1990 to 2013: findings from the Global Burden of Disease Study 2013. Lancet. 2016;388(10049):1081-1088.

2. Bruggmann P, Berg T, Ovrehus AL, et al. Historical epidemiology of hepatitis C virus (HCV) in selected countries. J Viral Hepat. 2014;21(Suppl 1):5-33.

3. WHO Guidelines Approved by the Guidelines Review Committee. Guidelines for the screening, care and treatment of persons with hepatitis C infection. Geneva: World Health Organization; 2014.

4. Lavanchy D. Evolving epidemiology of hepatitis C virus. Clin Microbiol Infect. 2011;17(2):107-115.

5. Umar S, Waheed Y, Ashraf M. Hepatitis B and hepatitis C viruses: a review of viral genomes, viral induced host immune responses, genotypic distributions and worldwide epidemiology. Asian Pac J Trop Biomed. 2014;4(2):88-96.

6. Furuta A, Salam KA, Akimitsu N, et al. Cholesterol sulfate as a potential inhibitor of hepatitis $\mathrm{C}$ virus $\mathrm{NS}_{3}$ helicase. J Enzyme Inhib Med Chem. 2014;29(2):223-229.

7. Hussain A, Mumtaz HM, Aslam MS, et al. Seroprevalence of transfusion based transmissible infections among clinically healthy donors in the community of Multan Pakistan. J Inf Mo Bio. 2015;3:47-55. 
8. Averhoff FM, Glass N, Holtzman D. Global burden of hepatitis C: considerations for healthcare providers in the United States. Clin Infect Dis. 201255(Suppl 1):10-15.

9. Umer M, Iqbal M. Hepatitis C virus prevalence and genotype distribution in Pakistan: Comprehensive review of recent data. World $J$ Gastroenterol. 2016;28;22(4):1684-700.

10. Umar M, Khaar HTB, Khurram M, et al. Anti-HCV Antibody Positivity of various sections of Pakistani Patients. J Coll Physicians Surg Pak. 2009;19(11):737-41.

11. Saleem M, Ahmad W, Sarwar J, et al. Frequency of hepatitis C in asymptomatic patients in District Headquarters Hospital Kotli, Azad Kashmir. J Ayub Med Coll Abbottabad. 2011;23(2):59-62.

12. Riaz S, Iqbal A. A review of hepatitis $\mathrm{C}$ in the general population in Pakistan. Viral Hepat J. 2016;220:74-81.

13. Idrees M, Riazuddin S. Frequency distribution of hepatitis $\mathrm{C}$ virus genotypes in different geographical regions of Pakistan and their possible routes of transmission. BMC Infect Dis. 2008;8:1-69.

14. Rafe MJ, Donahue H Q. Hepatitis B and hepatitis C in Pakistan: prevalence and risk factors. Int J Infect Dis. 2009;13(1):9-19.

15. Malik IA, Ahmad N, Luqman M, et al. Hepatitis C as a cause of chronic liver disease in northern Pakistan. J Pak Med Assoc. 1992;42:67-68.

16. Ayoub HH, Al Kanaani Z, Abu-Raddad LJ. Characterizing the temporal evolution of the hepatitis C virus epidemic in Pakistan. $J$ Viral Hepat. 2018:1-1
17. Qureshi H, Bile K, Jooma R, et al. Prevalence of hepatitis B and C viral infections in Pakistan: findings of a national survey appealing for effective prevention and control measures. East Mediterr Health $J$. 2010;16(Supple 1):15S-25S.

18. El-Zanaty F, Way A. Egypt Demographic and Health Survey 2008. Cairo, Egypt: Ministry of Health, El-Zanaty and Associates, and Macro International; 2009. 463 p

19. Qureshi H, Bile K, Jooma R, Alam S, et al. Prevalence of hepatitis B and $\mathrm{C}$ viral infections in Pakistan: findings of a national survey appealing for effective prevention and control measures. East Mediterr Health J. 2010;16(Supple 1):15S-25S

20. Alaei K, Sarwar M, Juan SC, et al. Healthcare and the Preventable Silent Killer: The Growing Epidemic of Hepatitis C in Pakistan. Hepat Mon. 2016;16(11):e41262.

21. World Health Organization. Combating Hepatitis $B$ and $C$ to Reach Elimination by 2030. Geneva, Switzerland: World Health Organization; 2016.

22. Punjwani R, Khatoon A, Fatima DS, et al. Practices and Policies of Infection Control and Prevention, Pakistan - A Review for Patient Safety. Medical Safety \& Global Health. 2016;5(1):1-3.

23. Anwar MN, Salahuddin A, Osman F, et al. Awareness about their disease in hepatitis B \& C patients from Afghanistan \& Pakistan attending Rehman Medical Institute. Journal of Rehman Medical Institute. 2016;1(2):1-1

24. The Global Viral Hepatitis Report. World Health Organization; 2017. 